\title{
Teachers' acceptance of ICT and its integration in the classroom
}

\begin{abstract}
Purpose: The purpose of this study is to identify factors that affect teachersômotivation to use information and communications technology (ICT) in the classroom. The study aims to determine the extent to which selected variables, such as personal experience, school environment and technological factors, influenced teachersôtendency to accept and utilize ICT in teaching. Design/methodology/approach: The study used primary data sources from Mazandaran, Iran, that included field notes and semi-structured interviews. Findings: Results revealed that adequate support from administrators, directives to teachers to use ICT, appropriate ICT skills and knowledge as well as adequate resources were important factors that influenced the utilization of ICT in the classroom. Findings also showed that insufficient technical support discouraged teachers from using ICT in teaching, while increasing adequate equipment and technical support in schools encouraged teachers in this respect. Research limitations/implications: Because this study was conducted on a small number of participants, its findings may not apply fully to other educational institutions. Practical implications: The results from this study would be helpful to educational departments and institutions in their formulation of policies to encourage the use of ICT in education. The findings would also give a better insight of what constitutes an environment that is conducive for learning where ICT is integrated into the classroom. Originality/value: By focusing on teachersôintention, this study provides important insights into which factors influence teacher attitude to use ICT into classroom. As a result, the finding will help the development of e-learning quality enhancement and assurance strategies.
\end{abstract}

Keyword: Attitudes; Education; Educational institutions; Motivation; Teachers; Technology 